\title{
Anticoagulant Activity of Averrhoa bilimbi Linn in Normal and Alloxan- Induced Diabetic Rats
}

\author{
Nurafifah Daud, Harita Hashim ${ }^{*}$ and Nurdiana Samsulrizal
}

Faculty of Applied Sciences, Universiti Teknologi MARA, 40450 Shah Alam, Selangor, Malaysia

\begin{abstract}
Hypercoagulation, which is often associated with diabetes mellitus may lead to several health problems such as thrombosis, stroke and heart attack. A plant with an anticoagulant effect would be beneficial to counteract these problems. An ethanolic extract of leaves and fruits of Averrhoa bilimbi Linn (Abe) (250 mg/kg) was orally administered to normal and diabetic male Wistar rats for 14 consecutive days. Samples of blood were then drawn after 14 days and centrifuged (5000 rpm,15 min) to obtain the plasma. Clotting time assays were carried out using a microtitre plate reader. The present study found that ethanolic extract of the leaves and fruits of $A$. bilimbi showed very significant anticoagulant effect on rats $(\mathrm{P}<0.01)$. The high level of oxalic acid in $A$. bilimbi, which range from 10.5 to $14.7 \mathrm{mg} / \mathrm{g}$ in green, unriped fruit and 8.45 to $10.8 \mathrm{mg} / \mathrm{g}$ in ripe fruit could provide the anticoagulation effect since oxalic acid is a metal cation chelator. Oxalate presumably binds to blood calcium, removing calcium ion from the blood, thus inhibiting the clotting process.
\end{abstract}

Keywords: Averrhoa bilimbi Linn, Oxalidaceae, belimbing buluh, anticoagulant, clotting time assay.

\section{INTRODUCTION}

Diabetes mellitus is the principal cause of morbidity and mortality in human populations [1], characterized by hyperglycemia, polydipsia and polyuria [2]. Hyperglycemia is a condition that arises when there is an excessive amount of glucose circulating in the blood plasma. The International Diabetis Federation (IDF) reported that approximately 366 million people have diabetes in 2011 and estimated that the number will increase to 552 million by 2030 [3]. In Malaysia, the prevalence of diabetes increased from $0.65 \%$ in 1960 to $2.1 \%$ in $1982,8.4 \%$ in 1996 and $11 \%$ in 2006 [4]. From these statistics, we can see that the cases of diabetes in Malaysia increase from year to year. The prevalence of diabetes is increasing due, among other reasons, to diet changes, aging, urbanization, and increasing prevalence of obesity and physical inactivity [5].

Several studies of the fluid phase coagulation have suggested that diabetes is associated with coagulation abnormalities, resulting in a state of thrombophilia. Thrombophilia or sometimes called prothrombotic states increase the risk of thrombosis [6]. The prothrombotic state is characterized by increased fibrinogen levels, increased plasminogen activator inhibitor (PAI)-1 and different abnormalities in platelet function. Due to this characteristics, thrombosis is promoted and thrombolysis is thus retarded [7]. Thromboembolic disorders such as pulmonary emboli, deep vein thrombosis, strokes and heart attacks are the main causes of morbidity and mortality in developed countries [8]. Several antithrombotic agents such as heparin have been used for the prevention and treatment of thromboembolic

*Address correspondence to this author at the Faculty of Applied Sciences, Universiti Teknologi MARA, 40450 Shah Alam, Selangor, Malaysia; Tel: +603-55444605; Fax: +603-55444562;

E-mail: harita709@salam.uitm.edu.my disorders. However, it has been reported that the use of heparin may be accompanied by side effects such as bleeding complications [9].

Averrhoa bilimbi Linn, a common plant in tropical Asia is a small-sized tree growing up to $15 \mathrm{~m}$ tall and $30 \mathrm{~cm}$ in diameter. The chemical constituents of A. bilimbi that have been identified include amino acids, citric acid, cyanidin-3$\mathrm{O}$-h-D-glucoside, phenolics, potassium ion, vitamin $\mathrm{A}$ and sugars [2]. The phenolic compounds which ranges from simple molecules (e.g. simple phenols, phenolic acids, phenyl-propanoids and flavonoids) to highly polymerized compounds (e.g. lignins, lignans, tannins, suberins and cutins) constitute one of the most numerous and ubiquitously distributed group of plant secondary metabolites [10]. The phenolic compounds are known for their powerful antioxidants and free-radical scavenging properties which can prevent the development of many chronic diseases [10].

Averrhoa bilimbi has been widely used in traditional medicine as a remedy for cough, cold, itches, boils, rheumatism, syphilis, diabetes, whooping cough and hypertension [11]. A study by [12] reported a significant decrease in blood glucose levels and food intake in streptozotocin-diabetic rats given the extracts of $A$. bilimbi fruits and leaves. A research has also been published on the hypoglycemic activity of semi-purified fractions of $A$. bilimbi [2]. To date, no research has been reported on their anticoagulant activity. Because of the recognized link between diabetes and hypercoagulation, medications that are able to treat diabetes with an added anticoagulant activity would be ideal.

\section{MATERIALS AND METHODS}

\subsection{Preparation of the Plant Ethanolic Extract}

The fresh leaves $(1 \mathrm{~kg})$ and fruits of A. bilimbi $(3 \mathrm{~kg})$ were sun dried and ground into powder. The powder was 
then wrapped in cotton cloth and soaked in $80 \%$ ethanol (2 L) for two days. The mixture was concentrated at $40^{\circ} \mathrm{C}$ by rotavapor (Buchi Labortechnik, Switzerland) and freeze dried to remove excess water. The crude was suspended in normal saline before use.

\subsection{Animals}

The used of rats in this study has the approval of The Research Committee on the Ethical Use of Animals, Universiti Teknologi MARA (REF: NO 13/2011). All experiments were performed on male Wistar rats aged approximately 7-8 weeks. The animals were acclimatized for one week before being used for the experiments. Standard pelleted diet and water were given ad libitum. Animals were maintained under a constant 12-hour light and dark cycle and an environmental temperature of $17-20^{\circ} \mathrm{C}$.

\subsection{Induction of Experimental Diabetes Mellitus}

The overnight fasted rats were made diabetic with alloxan monohydrate (Sigma). Alloxan monohydrate was freshly dissolved in normal saline $(0.9 \% \mathrm{NaCl})$ and administered intravenously at a dose of $160 \mathrm{mg} / \mathrm{kg}$ body weight. The rats were given $5 \%(\mathrm{w} / \mathrm{v})$ glucose solution in feeding bottles for the next $24 \mathrm{~h}$ in their cages to prevent hypoglycaemia following alloxan injection. After three days, the animals showing blood glucose levels $\geq 10 \mathrm{mmol} / 1$ were considered diabetic and were used for this study. Animals had free access to food and water following alloxan injection.

\subsection{The OGTT in Normal and Diabetic Rats}

Prior to an oral glucose tolerance test (OGTT), rats were fasted for 8 hours. Normal saline (control), a reference drug metformin $(500 \mathrm{mg} / \mathrm{kg})$, or each of three different doses of Averrhoa bilimbi leaves and fruits extract $(75,125$ and 250 $\mathrm{mg} / \mathrm{kg}$ ) were then orally administered to each group consisting of 4 rats. After thirty minutes, glucose $(3 \mathrm{~g} / \mathrm{kg})$ was orally administered to each rat by oral gavage. Blood samples were collected from the tail vein by tail milking at the beginning (just before the $A$. bilimbi extract and metformin administration), at 0 (just before the oral administration of glucose), at 60, 120, and $180 \mathrm{~min}$ after glucose load for the assay of glucose (Trinder method, Sigma Diagnostics, Sigma, St Louis, MO).

The OGTTs were performed on alloxan-induced diabetic rats using the same procedure as describe for normal rats.

\subsection{Experimental Procedure}

A total of 42 rats were divided into seven groups consisting six animals each: Group 1 and Group 2 served as normal control and diabetic control group respectively and received only normal saline, Group 3 served as positive control group administered the reference drug metformin (250 $\mathrm{mg} / \mathrm{kg})$, Group 4 and Group 5 served as normal treatment groups receiving the leaves and fruits extract of $A$. bilimbi respectively twice daily at a dose of $250 \mathrm{mg} / \mathrm{kg}$ while Group 6 and Group 7 served as diabetic treatment groups receiving the leaves and fruits extract of $A$. bilimbi respectively twice daily at a dose of $250 \mathrm{mg} / \mathrm{kg}$.

Prior to the start of treatment on day zero, the fasting blood glucose levels were measured after 8-hours of fasting.
Starting from treatment day zero, normal saline, metformin, leaves and fruits extract of A.bilimbi were administered orally by gavages twice daily for 14 consecutive days. On day 15, after an 8-hour fasting, blood was drawn from the vein and placed in ethylene diamine tetra acetate (EDTA) tubes. Subsequently, samples were centrifuged for $15 \mathrm{~min}$ at $5000 \mathrm{~g}$ at $4^{\circ} \mathrm{C}$ to obtain the plasma. Plasma was used for clotting time assays.

\subsection{Anticoagulant Activity}

Clotting time assays were used to determine the anticoagulant effect of $A$. bilimbi extract on rat plasma. The method of [13] was modified for microtitre plate analysis.

\subsubsection{Thrombin-Induced Clotting Time Assay}

The effect of Dimethylsulfoxide (DMSO, MERCK) on clot formation was determined since it is known to inhibit this process. The maximum concentration that could be used without significantly affecting clot formation is $2 \%(\mathrm{v} / \mathrm{v})$. A $40 \mu \mathrm{l}$ saline containing DMSO concentration of $2 \%(\mathrm{v} / \mathrm{v})$ was added to rat plasma $(100 \mu \mathrm{l})$ and incubated at room temperature for $5 \mathrm{~min}$. Bovine thrombin (Sigma) $(20 \mu \mathrm{l}$ at 5 $\mathrm{U} / \mathrm{ml}$ ) was then added and the rate of clot formation determined by following the increase of absorbance at 412 $\mathrm{nm}$ using a microtitre plate reader for $20 \mathrm{~min}$ at $1 \mathrm{~min}$ intervals. A negative control was performed using $2 \%(\mathrm{v} / \mathrm{v})$ DMSO in saline, which represents $100 \%$ activity. Heparin lithium (Sigma) was used as a positive control.

\subsection{Data Analysis}

The results are presented as means \pm S.E.M. The data were compared by paired sample T-test using SPSS software. Confidence interval of $90 \%, 95 \%$ and $99 \%$ were used for comparison. The values of $p<0.1, p<0.05$ and $p<$ 0.01 were considered to be statistically significant.

\section{RESULTS}

3.1. The Effects of Averrhoa Bilimbi on Glucose Tolerance in Normal and Alloxan-Induced Diabetic Rats

The blood glucose level increased in most of the groups after $60 \mathrm{~min}$ of the oral administration of glucose, as expected and gradually decreased to pre-glucose load level. In normal rats (see Table 1), leaves extract at a dose of 75 $\mathrm{mg} / \mathrm{kg}$ showed significant changes in blood glucose at 60 $\min (\mathrm{p}<0.1)$ and $120 \min (\mathrm{p}<0.05)$ when compared with vehicle-treated control group. However, the changes were in the form of increased of blood glucose (see Fig. 1a). For the fruits extract, a dose of $75 \mathrm{mg} / \mathrm{kg}$ showed significant attenuation in blood glucose at $180 \mathrm{~min}(\mathrm{p}<0.1)$ while a dose of $125 \mathrm{mg} / \mathrm{kg}$ showed significant attenuation in blood glucose at $60 \mathrm{~min}(\mathrm{p}<0.01)$ and $180 \mathrm{~min}(\mathrm{p}<0.1)$. Metformin showed significant attenuation in blood glucose only at $60 \min (\mathrm{p}<0.01)$.

In diabetic rats (see Table 1), only metformin showed a significant attenuation in blood glucose after $60 \mathrm{~min}$ and 120 min of the oral glucose load $(\mathrm{P}<0.1)$. For the extract, both leaves and fruits showed no significant differences in any of the three doses when compared to the vehicle-treated control group. However, of the three different doses, the highest dose which is $250 \mathrm{mg} / \mathrm{kg}$ showed better regulation in glucose 
Table 1. The Mean Percentage Changes in Blood Glucose Levels Over a 3-Hour Period for the Control, $A$. Bilimbi and MetforminTreated Normal and Diabetic Rats after Oral Glucose Load $(3 \mathrm{~g} / \mathrm{kg})$ in the Oral Glucose Tolerance Test

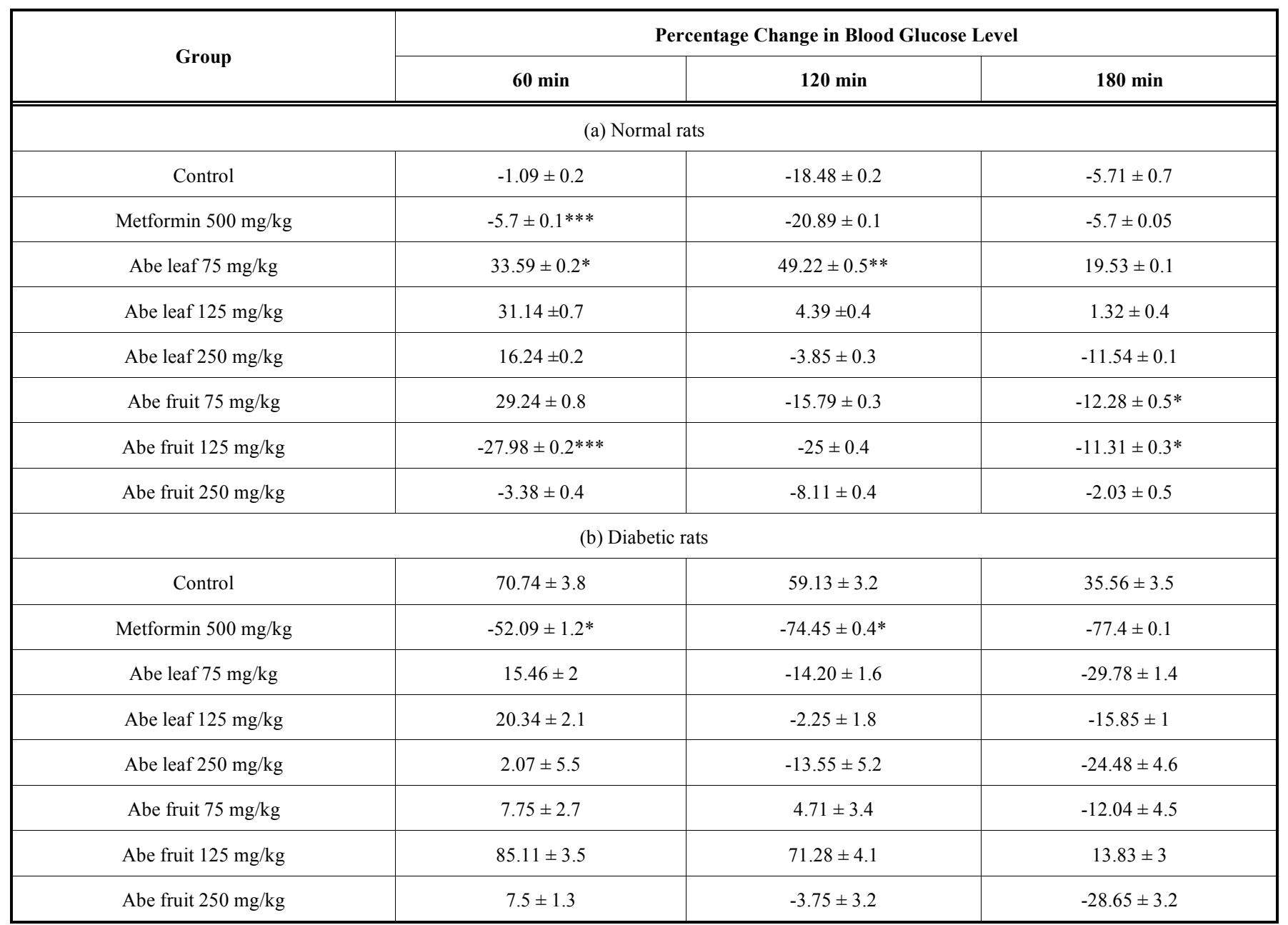

Values are expressed as the means \pm S.E.M, $n=4$. The percentage changes in blood glucose at 60,120 , and 180 min were calculated from the corresponding 0 -h value (just before the oral administration of glucose) in each group.

$*$ p-value $<0.1$ compared with corresponding control.

$* *$ p-value $<0.05$ compared with corresponding control

$* * *$ p-value $<0.01$ compared with corresponding control
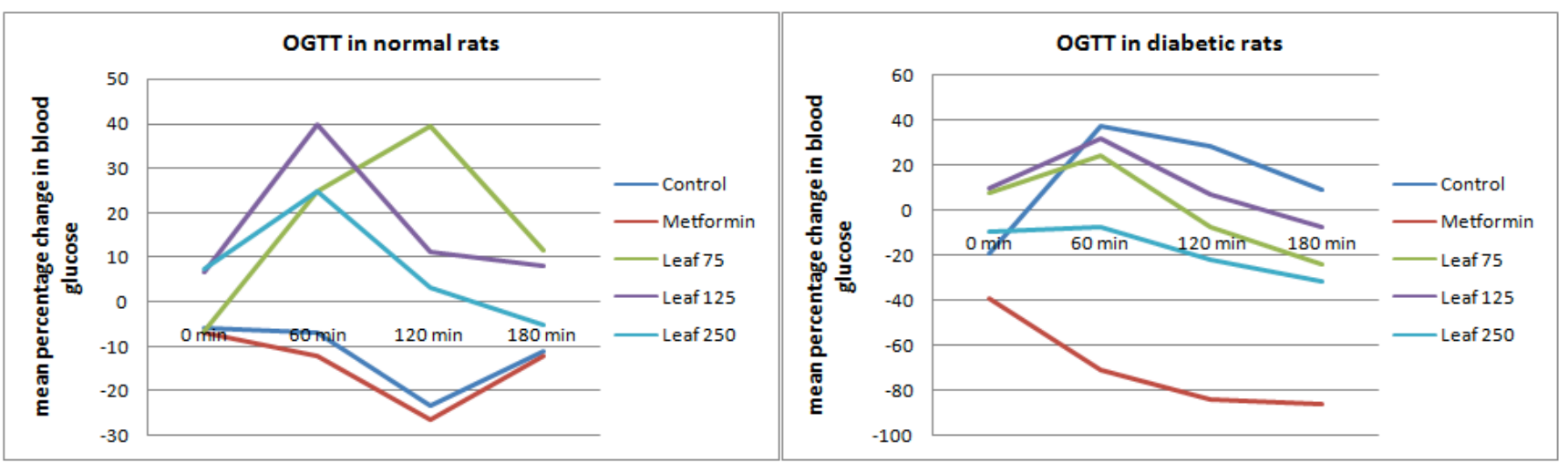

(a) 

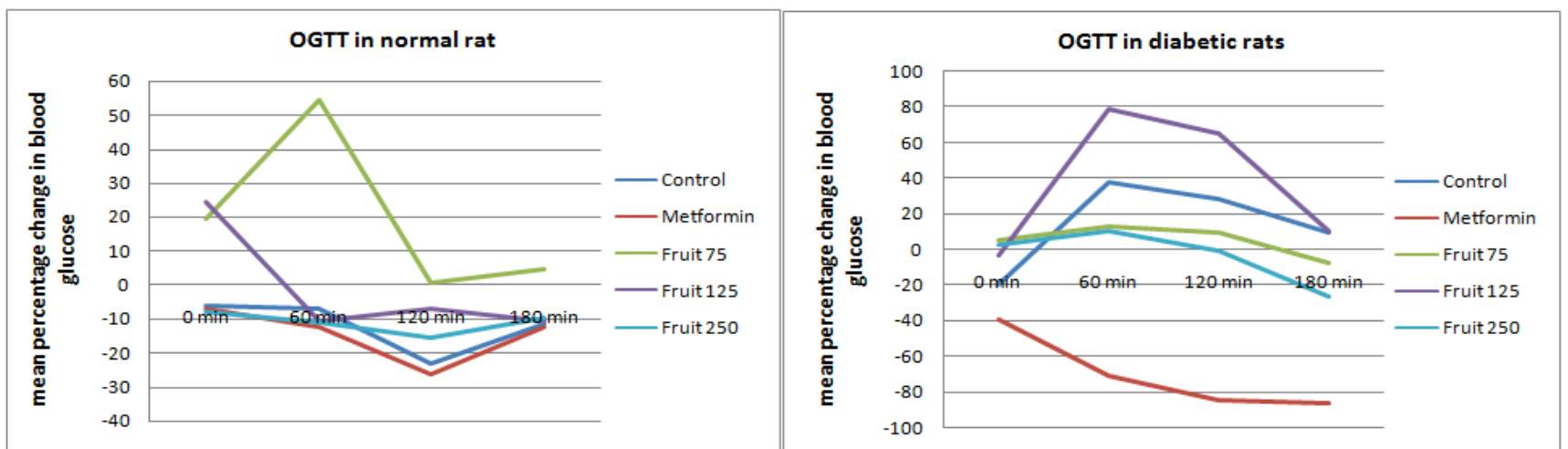

(b)

Fig. (1). Percentage change in blood glucose levels at 0,60,120, and 180 min calculated from the corresponding initial blood glucose value (just before the oral administration of extract) in normal and diabetic rats for (a) leaf extract and (b) fruit extract of Averrhoa bilimbi Linn.

Table 2. Blood Glucose, Body Weight and Organ Weight for (a) Normal Rats and (b) alloxan-induced Diabetic Rats Before and After Treatment with Vehicle (Normal Saline), Abe Leaves and Fruits Extract $(250 \mathrm{mg} / \mathrm{kg})$ and Metformin $(250 \mathrm{mg} / \mathrm{kg})$ Twice Daily for two-Weeks

\begin{tabular}{|c|c|c|c|c|c|c|}
\hline \multirow{2}{*}{ Group } & \multicolumn{2}{|c|}{ Blood Glucose $(\mathrm{mmol} / \mathrm{L})$} & \multicolumn{2}{|c|}{ Body Weight (g) } & \multicolumn{2}{|c|}{ Organ Weight (g) } \\
\hline & Before & After & Initial & Final & Liver & Kidney \\
\hline \multicolumn{7}{|c|}{ (a) } \\
\hline Control & $4.3 \pm 0.1$ & $4.2 \pm 0.2$ & $146.6 \pm 21.4$ & $190.4 \pm 18.7$ & $7.4 \pm 0.7$ & $1.7 \pm 0.1$ \\
\hline Abe leaf & $4.9 \pm 0.4$ & $4.6 \pm 0.2$ & $170.7 \pm 26.2$ & $231 \pm 22.3$ & $8.7 \pm 1$ & $1.8 \pm 0.2$ \\
\hline$\checkmark$ Abe fruit & $4.8 \pm 0.4$ & $4.7 \pm 0.4$ & $184.9 \pm 31.6$ & $215.9 \pm 25.9$ & $7.6 \pm 0.8$ & $1.8 \pm 0.1$ \\
\hline \multicolumn{7}{|c|}{ (b) } \\
\hline Control & $16.9 \pm 6.3$ & $9 \pm 2$ & $247.6 \pm 19.9$ & $245.4 \pm 20.4$ & $8.5 \pm 1.1$ & $2.2 \pm 0.3$ \\
\hline Metformin & $23.8 \pm 3.9$ & $5.8 \pm 1.6$ & $250.2 \pm 22.4$ & $231.5 \pm 15.6$ & $9.3 \pm 1.2$ & $2.3 \pm 0.3$ \\
\hline Abe leaf & $21.7 \pm 3.8$ & $16.4 \pm 3.8$ & $234.8 \pm 23$ & $213 \pm 29.6$ & $9.5 \pm 0.7$ & $2.8 \pm 0.4$ \\
\hline Abe fruit & $15.7 \pm 3.1$ & $10.1 \pm 3.5$ & $206.5 \pm 10.5$ & $219.1 \pm 22.1$ & $9.4 \pm 0.9$ & $2.6 \pm 0.3$ \\
\hline
\end{tabular}

Values are expressed as the means \pm S.E.M, $n=4-6$. The $\mathrm{p}$-value $<0.05$ compared with corresponding control.

since at $60 \mathrm{~min}$, it showed a lower percentage of increase in blood glucose (see Fig. 1a and Fig. 1b) and at $60 \mathrm{~min}$ and $180 \mathrm{~min}$, blood glucose level decreased gradually below the pre-glucose load level. A $250 \mathrm{mg} / \mathrm{kg}$ dose of both leaves and fruits extracts were then used for a subsequent 2-week study. Metformin at a dose of $500 \mathrm{mg} / \mathrm{kg}$ was found to cause hypoglycemia in rats. A dose of $250 \mathrm{mg} / \mathrm{kg}$ were also used for metformin.

\subsection{Daily Administration Effect of Averrhoa Bilimbi on Blood Glucose, Body Weight and Organ Weight in Normal and Alloxan-Induced Diabetic Rats}

The fasting plasma glucose for normal rats are within the normal range before and after the treatment (see Table 2a). There was only a slight decrease in blood glucose. The rats appeared to gain weight during the 14 days of treatment. It can be seen from the table, that the final weights are higher than their initial weight. There were no significant differences in blood glucose and body weight for the leaves and fruits extract-treated group after 14 days of treatment when compared to vehicle-treated control group. The weight of the liver and kidney for the extract-treated group also did not differ significantly with the control group.

In diabetic rats, the initial fasting plasma glucose is 4 times higher than in normal rats (see Table $\mathbf{2 b}$ ). There were reductions in blood glucose at the end of the treatment. However, the reduction in blood glucose for metformin and extract-treated group were not significant when compared to vehicle-treated control group. Generally, diabetic rats were losing their weights, although some of them did not. Rats in the control, metformin and leaves extract-treated groups showed reductions in body weights at the end of treatments while rats in the fruits extract-treated group appeared to gain weight. However, these changes are not statistically significant. Both the liver and kidney weights also showed no significant changes.

The leaves and fruits extract of $A$. bilimbi seem to be safe and consumable since there were no significant differences in body weight and organ weight after 2-weeks of oral administration when compared to the vehicle-treated control group. 


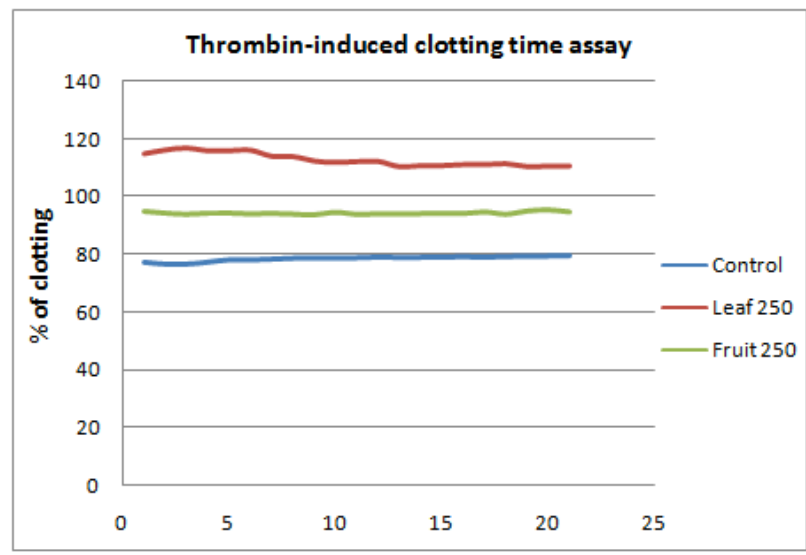

(a)

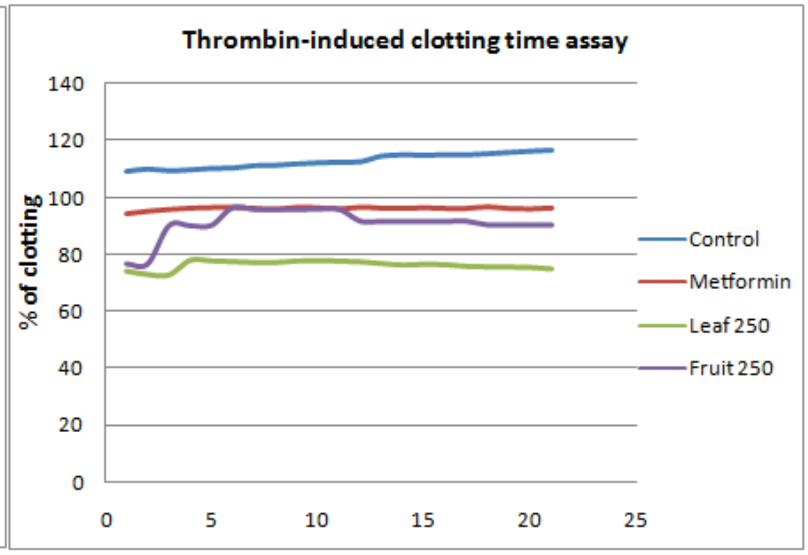

(b)

Fig. (2). Thrombin-induced clotting time assay for control, metformin (250 mg/kg), leaves extract (250 $\mathrm{mg} / \mathrm{kg})$ and fruits extract (250 $\mathrm{mg} / \mathrm{kg}$ ) treated group in (a) normal rats and (b) diabetic rats.

\subsection{Anticoagulant Activity of A. bilimbi in Normal and Alloxan-Induced Diabetic Rats}

The anticoagulant effect of $A$. bilimbi fruits and leaves extract was analyzed using thrombin-induced clotting time assay. The percentage of clotting was calculated over the corresponding positive control which is heparin.

In normal rats, both leaves and fruits extract of $A$. bilimbi showed significant differences in the percentage of clotting when compared to the vehicle-treated control group $(\mathrm{p}<$ 0.01 ). Leaves extract showed higher percentage of clotting compared to the fruits extract and control groups at the beginning (see Fig. 2a), but decreased gradually over time. Fruits extract showed little fluctuation in the clot formation while vehicle-teated control group showed gradual increase in clot formation over time.

In diabetic rats, there were also significant differences in the percentage of clotting for metformin, leaves and fruits extract of $A$. bilimbi when compared to the vehicle-treated control group $(\mathrm{p}<0.01)$. The control group showed a gradual increased in clot formation (see Fig. 2b), followed by metformin-treated group which showed very little increased in clot formation. Fruits extract-treated group showed great fluctuations in clot formation at the beginning, then decreased over time while leaves extract-treated group showed an increased clotting at the beginning, then decreased gradually over time.

The leaves and fruits extract of A. bilimbi showed an anticoagulant effect since the formation of clot was reduced over time. The extract took time to be activated and reacted with thrombin since there was an increased in clot formation at the beginning.

\section{DISCUSSION}

The leaves and fruits extract of $A$. bilimbi showed both antihyperglycemic and anticoagulant properties through thrombin-induced clotting time assay. In this assay, clotting was induced by the presence of thrombin. Thrombin will act upon the fibrinogen and clotting factor XIII contained in the plasma and convert it to fibrin and active form of factor XIII respectively [13]. In the presence of calcium ion, fibrin monomers bind to each other to formed polymeric fibers. Fibrin fibers will then form a loose network, stabilized by clotting factor XIII and trap the erythrocyte, thus forming a clot that stops blood flow.

The mechanisms involved in reducing the clot formation however are unclear. It is probably due to the high level of oxalic acid in $A$. bilimbi, since oxalic acid is a metal cation chelator. Oxalic acid has been identified as the main acid in A. bilimbi [14]. Oxalate presumably binds to blood calcium, removing calcium ion from the blood, thus inhibiting the polymerization of fibrin monomer. Subsequent crosslinked fibers were not able to form and trap the erythrocyte. Oxalate might also act by interfering with the action of thrombin, that is by inactivating the sodium $\left(\mathrm{Na}^{+}\right)$ions. Thrombin is a $\mathrm{Na}^{+}-$ activated allosteric serine protease [15], optimally actived in the presence of $\mathrm{Na}^{+}$[16]. Binding of $\mathrm{Na}^{+}$at the allosteric site converts thrombin from a low activity slow $\left(\mathrm{Na}^{+}\right.$-free) to a high activity fast $\left(\mathrm{Na}^{+}\right.$-bound) form [17]. $\mathrm{Na}^{+}$binding are required for optimal cleavage of fibrinogen [15]. Due to the allosteric nature of thrombin, any effect that destabilizes $\mathrm{Na}^{+}$ binding, stabilizes the slow form and produces an anticoagulant effect by prolonging the clotting time through reduced fibrinogen cleavage [15].

\section{CONCLUSION}

A. bilimbi possess antihyperglycemic and anticoagulant effects, thus reducing the probability of thrombus formation in blood vessels. This plant may have the potential to reduce the risk of stroke, venous thrombosis, heart attack and other metabolic syndromes associated with clot formation. Apart from treating diabetes, it could be used to reduce the formation of clots during surgical procedures.

\section{CONFLICT OF INTEREST}

The authors confirm that this article content has no conflicts of interest.

\section{ACKNOWLEDGEMENTS}

The authors wish to thank Universiti Teknologi MARA for the Dana Kecemerlangan research grant in aid of this study [600-RMI/ST/DANA 5/3/Dst (277/2009)]. 


\section{REFERENCES}

[1] Steppan, C.M.; Bailey, S.T.; Bhat, S.; Brown, E.J.; Banerjee, R.R.; Wright, C.M.; Patel, H.R.; Ahima, R.S.; Lazar, M.A. The hormone resistin links obesity to diabetes. Nature, 2001, 409(6818), 307312.

[2] Tan, B.K.H., Tan, C.H., Pushparaj, P.N. Anti-diabetic activity of the semi-purified fractions of Averrhoa bilimbi in high fat diet fedstreptozotocin-induced diabetic rats. Life Sci., 2005, 76, 2827-2839.

[3] International Diabetes Federation. 2011 Diabetes. In the global burden.[ Retrieved: November 21, 2011] Available from: http://www.idf.org/diabetesatlas/5e/the-global-burden.

[4] Tan, M.Y.; Margarey, J. Self-care practice of Malaysian adults with diabetes and sub-optimal glycaemic control. Patient Educ. Couns., 2008, 72(2), 252-267.

[5] Moreira, E.D., Neves, R.C.S., Nunes, Z.O., Almeida, M.C.C., Mendes, A.B.V., Fittipaldi, J.A.S.; Ablan, F. Glycemic control and its correlates in patients with diabetes in Venezuela: Results from a nationwide survey. Diabetes Res. Clin. Pract., 2010, 87(3), 407414.

[6] Carr, M.E. Diabetes mellitus: A hypercoagulable state. J. Diabetes Complications, 2001, 15(1), 44-54.

[7] Vinik, A.I., Erbas, T., Park, T.S., Nolan, R.; Pittenger, G.L. Platelet dysfunction in type 2 diabetes. Diabetes Care, 24, 2001, 14761485 .

[8] Derkacz, A.; Nowak, T.; Gorawski, M.; Bezubka, J.; Szelemej, R. Thrombosis within the area of muscle bridge as a cause of myocardial infarction. Kardiol. Pol., 2011, 69(3), 291-292.
[9] Yoon, S.J., Yu, M.A., Pyun, Y.R., Hwang, J.K., Chu, D.C., Juneja, L.R.; Moura o, P.A.S. The nontoxic mushroom Auricularia auricula contains a polysaccharide with anticoagulant activity mediated by antithrombin. Thromb Res., 2003, 112, 151-158.

[10] Vadivel, V.; Biesalski, H.K. Contribution of phenolic compounds to the antioxidant potential and type II diabetes related enzyme inhibition properties of Pongamia pinnata L. Pierre seeds. Process Biochem.,2011, 46(10), 1973-1980.

[11] Goh, S.H., Chuah, C.H., Mok, J.S.L. and Soepadmo, E. Malaysian Medicinal Plants for the Treatment of Cardiovascular Diseases. Pelanduk Publication: Malaysia., 1995, pp.62-63.

[12] Pushparaj, P.N., Tan, B.K.H.; Tan, C.H. The mechanism of hypoglycemic action of the semi-purified fractions of Averrhoa bilimbi in streptozotocin-diabetic rats. Life Sci., 2001, 70, 535-547.

[13] Kee, N.L.A., Mnonopi, N., Davids, H., Naudé, R.J. and Frost, C.L. Antithrombotic/anticoagulant and anticancer activities of selected medicinal plants from South Africa. Afr. J. Biotechnol., 2008, 7(3), 217-223.

[14] Joseph, J; Mendonca, G. Oxalic acid content of carambola (Averrhoa carambola L.) and bilimbi (Averrhoa bilimbi L.). Proc Intram Soc Trop Hortic., 1989, 33, 117-120.

[15] Di Cera, E. Thrombin. Mol. Med., 2008, 29(4), 203-254.

[16] Orthner, C.L.; Kosow, D.P. Evidence that human alpha-thrombin is a monovalent cation-activated enzyme. Arch. Biochem. Biophys.,1980, 202, 63-75.

[17] Wells, C.M. and Di Cera, E. Thrombin is a $\mathrm{Na}(+)$-activated enzyme. Biochemistry, 1992, 31, 11721-11730.

(C) Daud et al.; Licensee Bentham Open .

This is an open access article licensed under the terms of the Creative Commons Attribution Non-Commercial License (http://creativecommons.org/licenses/by$\mathrm{nc} / 3.0 /$ ), which permits unrestricted, non-commercial use, distribution and reproduction in any medium, provided the work is properly cited. 